\title{
A GRAMÁTICA DE PÂNINI
}

\section{Jorge Bertolaso Stella}

S. Paulo

A India é chamada "o pais dos milagres" e é também o país das "muitas linguas". Com certa reserva, contam-se 179 linguas e 544 dialetos.

Supōe-se que os primeiros habitantes da India tivessem penetrado, vindos de outros paises. Segundo as mais recentes opiniōes dos antropólogos, cêrca de 6 raças distintas, subdivididas nas suas ramificaçōes, foram para êsse país em épocas pré-históricas e contribuíram para a formação da população indiana. As línguas da India, diz Chatterii (1), derivam das linguas trazidas por essas gentes nas épocas várias. O povo mais antigo dessa região foi o "negrito" ou "negróide", proveniente da África, o qual desapareceu com a sua língua, tendo deixado poucos traços da sua permanência.

Vários grupos lingüísticos têm sua sede na India, e, dentre êles, o grupo índo-europeu. Dois povos, os quais estudados à luz do Rig-Veda e do Avesta, tinham grande afinidade entre si, separando-se, povoaram a India e o Irä, diferenciando-se por novas caracteristicas lingüísticas, religiosas e sociais (2). Ários são pròpriamente chamados os Indo-europeus que pertencem a tal comunidade, ao ramo oriental asiático, isto é, da sua grande família, e árias as suas línguas, do antigo indiano aryâ, ârya, avéstico airya-ant. Per. ariya-.

Em data que não se pode precisar, dizem ainda os autores citados, mas provàvelmente anterior ao primeiro milênio a. C., uma parte da comunidade ária, da sede comum, ao norte da Pérsia, desceu para o sul, zo hodierno Afghânistân e à Pérsia; a outra,

(1) - Chatterii S. K. -Letterature medicevali e Moderne nel subcontinente indiano. Le Giviltà dell'Oriente, Literature, Lingue, Roma 1957, p. 584.

(2) - Ballini A. e Vallauri M. - Lineamenti d'una storia delle lingue e della literatura antica e medioevale dell"India. Roma 1943, p. 13 
em direção do sudeste, através dos passos de Hindu-Kush, entrou, ao longo do vale Kâbul, na india, fazendo sede no Panjab, onde sustentou luta com os habitantes, aborigines, luta esta que o RigVeda deixou recordações em cenas de combates, entre brancos e pretos.

Abandonada a regiāo ao norte do Hindu-Kush, o ramo dos Árias que do noroeste desceu à Índia, fizeram como sua sede o hodierno Panjab, o país dos cinco rios. Lá, dizem Ballini e Vallau$r i$, se desenvolveu e evoluiu a mais antiga forma da linguagem indo-ária, o antigo indiano, forme diversa daqueia que hoje é conhecida pelos hinos do Rig-Veda, que expressam notável laboração lingüística. Com o correr dos tempos e em sucessivas levas, os que falavam tal dialeto se dirigiam cada vez mais para o oriente e para o meio dia, fixando a sua sede entre o Panjab e a moderna Allahabad, no pedaço de terra que a tradição épica chama Madhyadeça, "o país do meio" da Âryâvarta "a terra dos ários". Centro da civilização, tornou-se assim o pedaço de terra entre o Ganges e a Jumna, chamado hoje Doâb (dois rios) gangético, que tem ao seu oriente o hodierno Oudh.

Em confronto à língua do Rig-Veda, grande redução de formas gramaticais apresenta a língua do Atharva-Veda e dos Brâhmana e particularmenté o sânscrito clássico, o qual foi fixado pelos gramáticos, cuja obra culminou com Pânini. $O$ sânscrito fixado sôbre regras gramaticais foi chamado "(língua) perfeita, elaborada, refinada, purificada". O termo sanskrta aparece pela primeira vez no Râmâyana como têrmo lingüístico "acabado, perfeito": faz alusão aos samskâra, isto é, aos procedimentos da "perfeição" gramatical (e mais tarde também estilística), graças aos quais a matéria bruta da linguagem, a prakrti, é conduzida à perfeição formal (1); ou, como diz poèticamente o mais antigo escritor da linguagem, o autor do hino X.71 do Rig-Veda, é "clarificada" como se joeira o grão com o auxílio do crivo" (sâktum iva titaunâ punântah). Renou, em nota, observa ainda quanto à samskâra: êste sentido de samskâra (preludiando o emprêgo lingüístico de samskrta) encontra-se no Nir. I. 12, literalmente: "formação gramatical correta". A interpretação de sâmskrta (ant.) ou -tâ-(fem., scil.: bhâsâ) figura, por exemplo, na Sdbhâsâcandrikâ 4 "chama- 
se samskrta a língua que foi elevada à perfeição formal pelos sistemas de Kumâra, Pânini e outros".

Referindo-se à pureza da língua, Renou prossegue: Existe sem dúvida uma conotação de ordem espiritual: samskrta evoca também o resultado das purificaçōes religiosas, dos sacramentos (sâmskâral pelos quais passam os individuos de alta casta, entre - nascimento e a morte. A idéia da gramática como instrumento de purificação está presente no mais antigo comentário gramatical a Paspasâ do Mahâbhâsya, como através de tôda a Mîmâmsâ.

Essa língua "elaborada, perfeita" surgiu em oposição às línguas indo-árias, diferenciadas umas das outras, porém hoje tôdas recolhidas sob a designação comum de médio indiano que, formado diretamente das línguas indo-árias, da mesma região do antigo indiano ou de outras, foram chamadas prakrta "naturais", não ellaboradas, de prakrti (natureza).

E bom observar que tôdas as línguas da India, desde os tempos antigos, podem ser consideradas prákritas verdadeiras e próprias. Assim a língua do Rig-Veda embora tivesse sido elaborada, "fixada escrupulosamente como língua religiosa", porque não ainda purificada, é considerada o exemplo histórico mais antigo do prákrito que C. A. Grierson chama primário, como os dialetos itálicos comparados ao latim literário de Roma.

Fixado o antigo indiano, por obra purificadora dos gramáticos, a tendência popular em manter formas não clássicas de gramáticas, persistindo na forma sintética ou tornando sempre mais fácil a pronúncia com o substituir aos ditongos um só homogêneo vocálico (por exemplo sânsc.: Airâvana - nome próprio do elefante de Indra, Kaumudî "luz lunar" prak, Erâvana-, Kamudî̀), assimila as consoantes, para que fôsse evitada a dureza da pronúncia dos nexos doces (sâns. arka - "sol", phalgu- "pequeno", -bhakta"dividido", prak. akka-, phaggu-, bhatta-) trouxe a um novo estado lingüistico, que pode ser chamado prákrito secundário, aquêle mencionado do médio indiano.

Evoivendo a lingua, como é natural, seguiu-se o indiano moderno ou neo-indiano. Este surgiu 15 séculos depois do médio indiano e dividiu-se em grande quantidade de línguas e dialetos.

(1) - Renou L. -Histoire de la langue sanserite, Paris 1956, p. 5, 6. 
O sânscrito ocupou lugar de destaque na cultura e na civilização indiana, usado nas disputas religiosas em público; lingua dos reis, dos sábios, dos brâhmanes de grau elevado, dos ministros, dos generais. Esse idioma, vivo, foi sempre falado como diferença dos vários prákritos (médio indiano, prákrito secundário) que, embora contrapondo-se às línguas vulgares (prákritos terciários) e tendo com o tempo conseguido posição literária, ficaram sendo línguas dos ofícios e refletiam as tendências do falar local e da família. Porém dado o fato que tais prákritos ameaçavam invadir a língua, que, embora variada, representava, desde os tempos antigos, o elemento conservador da civilização brahmânica, a verdadeira civilização da India, tornou-se necessária a obra "purificadora" dos gramáticos, os quais, em regras esquemáticas e de fácil aprendizagem mnemônica, fixaram tôdas as normas da língua. Essa tarefa foi concluída por Pânini na sua célebre gramática. Mas que Pânini se dirigia aos que falavam, aos que entendiam, isto é, dava normas para a língua de uso corrente, demonstram os têrmos da cavalariça, de cozinha, de conversação, etc., que se encontram na sua gramática.

Do problema da época em que viveu Pânini trataram, em discussāo calorosa, os indianistas Böhtlingk, Weber e Godstucker. Postas à margem opiniões que hoje não são tomadas em consideração, dado o progresso das pesquisas, lembramos que Böhtlingk, baseado em Samaveda, afirma que Pânini foi discipulo de Varasha, o qual viveu em Pàtaliputra sob o reinado de Nanda, pai de Candragupta, e dá como época provável do célebre gramático 0 ano de 350 a. C. Hoje admite-se como época assentada o IV século a. C. Supõe-se que êle seja originário do noroeste, da cidadezinha de Sâlatûra no Gandhâva, segundo a tradição. Segundo o Kaus. Br. VII, 6, a região do norte (isto é, do N. O.) é aquela onde a língua é falada com mais discernimento: "le gens vont au Nord pour apprendre la langue; qui en revien de la pour l'enseigner, on l'ecoute, car cette region du language est reconnue (comme exemplaire)" (1). Queremos citar a opinião particular de O. Franke que afirma ser a língua de Pânini a língua de Leste.

Pânini teve uma longa linha de predecessores, porque não é admissível que uma obra obra tão perfeita como a sua, tenha apa-

(1) - Renou L. - Histoire de la Langua Sanscrite - Paris, 1956 - p. 67. 
recido sem antecedentes (1). Ele cita dez autoridades, das quais nada sabemos. Menciona, além disso, genèricamente os prâñcah (orientais) e os udañcah (setentrionais); o têrmo pûrvasûtra em Patañjali, segundo F. Kielharn, se refere a tratados pré-paninianos.

A Astâdhyâyi (os oito capítulos) de Pânini, coleção de 3996 sûtra ou "aforismos", é a sua célebre gramática. Esses aforismos são concisos, e exigem, para atendê-los, um comentário, o que felizmente existe.

Essa gramática de Pânini tem sido estudada por muitos sábios de vários países (2). Citamos apenas algumas como sejam a S. Ch. Vasu, 1891, com tradução e glosas inglèsas, fundadas sobretudo na Kâçikâ; a 2a. edição de O. Böhtlingk, 1887; a la. em 1838; apesar de algumas imperfeições, ela é ainda um modêlo precioso; a edição de Renou, 1947, é clara e apreciável sob todos os aspectos. llustres sanscritólogos, como entre outros, H. T. Colebrook, Max Müller, e especialmente Th. Benfey, basearam suas gramáticas na Astâdhyâyî de Pânini.

Esse livro contém a primeira e a mais importante descrição gramatical que' possuimos no domínio indiano. A gramática sânscrita de Pânini é a mais vasta e a mais metódica, o mais completo trabalho gramatical de tôda a antiguidade, e, em certo sentido, de todos os tempos e de tôdas as nações, no sentir de Fumi. Expõe o célebre gramático, com uma exatidão admirável, as doutrinas dos sons, das formas, das divisões, nominais, verbais, etc., e acrescenta a lista das raizes e dos temas, que têm sido para a nova lingüística de uma luz e auxílio incontestáveis.

As raizes, é verdade, tinham sido reunidas em listas antes de Pânini, mas êste, dado o engenho que the era peculiar, modificou-as e aperfeiçoou-as. Com essa gramática, êle elevou o sânscrito à lingua literária. $O$ trabalho do sábio indiano, que têm cêrca de 2.300 anos, é tão completo que língua alguma hoje poderá fàcilmente gloriar-se de possuir outro semelhante. E sôbre essa gramática de Pânini que, em parte, está edificada a filologia moderna.

(1) Renou L. - La Durghata vitti de Saranadeva, etc. - Vol. I - Paris, 1940 - p. 6

(2) Renou L. - La Durghata vitti de Sàranadeva, etc. - Vol. 1 - Paris 1940 - p. 9. 